\title{
Gambaran Tingkat Pengetahuan Ibu tentang Feeding Rules pada Batita Gerakan Tutup Mulut (GTM)
}

\author{
Nur Chumairoh ${ }^{1 *}$, Indah Ika Suryaningsih H. ${ }^{2}$ \\ 1,2Departemen Pelayanan Medis, Rumah Sakit Umum Universitas Muhammadiyah Malang
}

\begin{abstract}
ABSTRAK
Pemberian makan merupakan bagian penting dari kehidupan bayi dan anak di bawah tiga tahun (batita) dan sebagian besar interaksi orangtua dan anak terjadi pada saat pemberian makan. Namun, sekitar 50 lebih orang tua melaporkan bahwa anak mereka mengalami masalah atau kesulitan makan. Sebanyak 1-2\% bayi mengalami gerakan tutup mulut (GTM) yang serius sehingga menyebabkan malnutrisi. Feeding rules dapat membantu batita untuk mengatur dan mengatasi masalah makannya sendiri. Penelitian ini bertujuan untuk mengetahui tingkat pengetahuan ibu tentang feeding rules pada batita yang mengalami Gerakan Tutup Mulut (GTM) di wilayah kerja Rumah Sakit Umum Universitas Muhammadiyah Malang. Jenis penelitian ini adalah penelitian deskriptif, dengan menggunakan desain observasi. Sampel dalam penelitian adalah ibu yang mempunyai anak usia 1-3 tahun yang pernah mengalami GTM (Gerakan Tutup Mulut) sebanyak 67 responden. Teknik pengambilan sampel secara purposive sampling. Responden mengisi kuisioner yang berupa google form. Uji validitas dan reliabilitas telah dilakukan dengan nilai Cronbach Alpha 0,899. Analisa data yang dilakukan peneliti adalah analisa univariat. Dari hasil penelitian didapatkan tingkat pengetahuan ibu tentang feeding rules pada anak usia 1-3 tahun yang mengalami Gerakan Tutup Mulut (GTM) adalah baik yaitu, sebanyak 38 responden (57\%), sedangkan yang memiliki tingkat pengetahuan kurang sebanyak 29 responden (43\%). Hasil ini menunjukkan meski tingkat pengetahuan ibu tentang feeding rules baik, tidak menjamin anak tidak mengalami GTM. Hal ini dapat dikarenakan adanya faktor internal lain didalam tubuh anak itu sendiri. Kesimpulan dari penelitian ini adalah tingkat pengetahuan ibu tentang aturan feeding rules adalah baik pada batita yang mengalami GTM.
\end{abstract}

Kata kunci: feeding rules; GTM; batita; tingkat pengetahuan ibu

\begin{abstract}
Introduction: Feeding is an important part of the life of infants and children under three years (toddler) and most parent-child interactions occur at feeding time. However, 50 of parents reported that their children have feeding problems. About 1-2\% of babies experience a serious Mouth Shut Movement (MSM) that can lead to malnutrition. Feeding rules can help toddlers to manage and to overcome their own eating problems. Purpose: This study aims to determine the knowledge about Feeding rules of mothers who have children aged 1-3 years with Mouth Shut Movement (MSM) in the area of the General Hospital of the Muhammadiyah University of Malang. Methods: This study is a descriptive study and uses an observational design. The participants were selected through purposive sampling among mothers who have children with Mouth Shut Movement (MSM) aged 1-3 years with total of 67 respondents. Respondents were asked to fill out a questionnaire in the form of a google form. Validity and reliability tests have been carried out with a Cronbach Alpha value of 0.899 and univariate analysis was used for the data analysis. Results: The result shows that 38 respondents (57\%) have good knowledge about feeding rules while 29 respondents (43\%) have lacked it. Discussion: It indicates that even though the mother's level of knowledge about feeding rules is good, it did not guarantee that the children did not experience Mouth Shut Movement (MSM). This could be due to other internal factors in the child's own body. Conclusion: The conclusion is knowledge about feeding rules of mothers who have children aged 1-3 years with Mouth Shut Movement (MSM) is good.
\end{abstract}

Keywords: feeding rules; Mouth Shut Movement; toddler; mothers' knowledge

*Korespondensi penulis:

Nama : Nur Chumairoh

Instansi : Rumah Sakit Umum Universitas Muhammadiyah Malang

Alamat : Jl. Tlogomas No.45, Landungsari, Kec. Dau, Kota Malang, Jawa Timur, Telp: (0341) 561666

Email : nurchumairoh7@gmail.com 


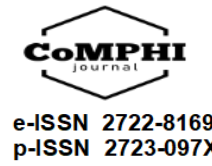

\section{Pendahuluan}

Pemberian makan merupakan bagian penting dari kehidupan bayi dan anak di bawah tiga tahun (batita) dan sebagian besar interaksi orangtua dan anak terjadi pada saat pemberian makan. Ibu sangat mempunyai peranan penting dalam pertumbuhan dan perkembangan Bayi dan Balita. Khususnya pengetahuan ibu memiliki pengaruh kepada pola pikir dan tingkat kepedulian untuk memberikan asupan makan yang tepat untuk anaknya ${ }^{1}$. Pemberian makan pada bayi dan batita dianggap sebagai proses yang natural, namun sekitar 50 lebih orang tua melaporkan bahwa anak mereka mengalami masalah atau kesulitan makan ${ }^{2}$.

Studi di Chicago melaporkan bahwa masalah perilaku makan yang paling sering dijumpai pada bayi adalah tidak selalu lapar pada saat makan sebesar 33\%, sedangkan masalah perilaku makan pada batita meliputi tidak selalu lapar saat jam makan sebesar 52\%, mencoba mengakhiri makan setelah beberapa suapan sebesar 42\%, "pickyeating" sebesar 35\%, dan kuatnya preferensi makanan tertentu sebesar $33 \%^{14}$. Sebanyak $1-2 \%$ bayi mengalami masalah makan yang serius dan berkepanjangan ${ }^{2}$.

Gerakan Tutup Mulut atau lebih dikenal dengan istilah GTM yaitu kesulitan makan atau menolak makan yang sering kali dialami anak pada tahun pertama. Usia 6 - 9 bulan merupakan masa kritis dalam memperkenalkan makanan padat secara bertahap ${ }^{14}$. Penyebab GTM yang lain adalah komposisi yang diberikan atau dikenalkan pada bayi tidak adekuat, tekstur yang tidak sesuai dan cara pemberian makanan pendamping air susu ibu yang tidak tepat ${ }^{4}$.

Penelitian di Jakarta, pada tahun 2011 menunjukkan bahwa inappropriate feeding practice merupakan salah satu penyebab masalah makan yang bermakna (30\%) pada anak usia 1-3 tahun. Inappropriate feeding practice didefinisikan sebagai perilaku makan yang salah, yaitu tidak mengikuti Feeding rules atau pemberian makanan yang tidak sesuai usia. Praktek pemberian makan yang salah, meliputi jenis makanan dan perilaku makan, juga berkontribusi besar terhadap terjadinya inappropriate feeding practice ${ }^{2,12}$.

Selain itu, masalah makan berpotensi menyebabkan gangguan kognitif dan perilaku, serta dikaitkan dengan gangguan cemas dan kelainan makan (eating disorder) pada anak, remaja, dan dewasa muda. ${ }^{2,12}$ Saat anak menunjukkan kondisi adanya masalah makan, tidak jarang orang tua mencari solusi dengan memberikan anak multivitamin atau suplemen, bahkan tidak sedikit orang tua beranggapan bahwa makan dapat diganti dengan minum susu. ${ }^{13}$ Pemahaman yang salah ini tanpa disadari oleh orang tua atau pengasuh akan mengakibatkan anak kekurangan gizi atau malnutrisi.

Penelitian di Jakarta menunjukkan Prevalensi gangguan makan anak usia 4-6 tahun sebesar 33,6\%; 44,5\% diantaranya menderita malnutrisi ringan hingga sedang dan $79,2 \%$ mengalami malnutrisi yang telah berlangsung lebih dari 3 bulan. ${ }^{3}$ Hasil Riset Kesehatan Dasar (Riskesdas) tahun 2018 menunjukkan bahwa terdapat $17,7 \%$ balita Indonesia mengalami gizi buruk dan gizi kurang, hal ini tentu lebih tinggi dibanding dengan target RPJMN yakni sebesar $17 \%$. Sedangkan proporsi balita dibawah dua tahun (baduta) yang pendek dan sangat pendek sebesar $29,9 \%$, hal ini tentunya lebih tinggi dari target RPJMN sebesar 28\% dan badan kesehatan dunia (WHO) sebesar 20\%. ${ }^{3}$

Pada anak yang mengalami inappropriate feeding practice dapat terjadi secara primer akibat kurangnya pengetahuan orangtua megenai pemberian makan yang benar. ${ }^{2}$ Ketidakmampuan orangtua untuk memberi makan secara benar dapat mengakibatkan masalah makan. Ketidakmampuan ini dapat disebabkan karena kurangnya pengetahuan mengenai empat aspek cara pemberian makan yang benar, yaitu (1) tepat waktu, (2) kuantitas dan kualitas makanan, (3) penyiapan dan penyajian yang higienis, serta (4) pemberian makan yang sesuai dengan tahapan perkembangan anak dengan menerapkan Feeding rules. ${ }^{2,12}$ 
Feeding rules adalah aturan dasar pemberian makan. Aturan dasar pemberian makan ini harus diperhatikan selama proses pemberian makan. Feeding rules ini harus dinilai saat ditemukan anak dengan masalah makan. ${ }^{2}$ Feeding rules menurut WHO meliputi: jadwal, lingkungan, dan prosedur makan. Jadwal makan menurut WHO sehari meliputi adanya jadwal makan utama, dan makan selingan yang teratur, serta durasi makan maksimal 30 menit. Anak tidak diberi air minum kecuali hanya disela makan utama. ${ }^{12}$

Lingkungan saat makan yang mendukung akan tercipta kebiasaan makan yang baik tanpa adanya paksaan. Tidak ada distraksi saat makan, misalnya $\mathrm{TV}$, game, mainan, atau permainan yang lain. Serta tidak adanya hadiah bila anak telah makan. Prosedur saat makan dengan mendorong anak untuk makan sendiri, menawari anak tanpa ada paksaa, bila setelah 10-15 menit anak tetap tidak mau makan, akhiri proses makan. ${ }^{9}$

IDAI merekomendasikan orang tua atau pengasuh menerapkan praktik pemberian makan yang benar dan Feeding rules sejak anak dikenalkan pada MPASI. ${ }^{12}$ Feeding rules dapat membantu batita untuk mengatur dan mengatasi masalah makannya sendiri. Melihat fenomena ini peneliti ingin meneliti tentang gambaran tingkat pengetahuan ibu tentang aturan dan jadwal makan (feeding rules) terhadap masalah Gerakan Tutup Mulut (GTM) pada anak 1-3 tahun.

\section{Metode}

Metode penelitian yang digunakan adalah penelitian deskriptif, dengan rancangan studi kasus. Penelitian deskriptif yaitu suatu metode penelitian yang dilakukan dengan tujuan utama untuk menggambarkan suatu keadaan secara objektif. Penelitian ini menggunakan desain observasi dimana penelitian hanya bertujuan untuk melakukan pengamatan dan non eksperimental. Penelitian ini menggunakan rancangan studi kasus yaitu salah satu jenis rancangan penelitian yang mencakup satu unit penelitian secara intensif. Studi kasus dibatasi oleh tempat dan waktu, serta kasus yang dipelajari berupa peristiwa, aktivitas, atau individu dan menggambarkan atau mendeskripsikan tingkat pengetahuan ibu tentang aturan dan jadwal makan (Feeding rules) terhadap masalah Gerakan Tutup Mulut (GTM) pada anak 1-3 tahun.

Sampel dalam penelitian adalah ibu yang mempunyai anak usia 1-3 tahun yang pernah mengalami GTM (Gerakan Tutup Mulut) di wilayah Rumah Sakit Umum Universitas Muhammadiyah Malang. Jumlah sampel sebanyak 67 responden. Teknik pengambilan sampel secara purposive sampling. Kriteria inklusi sampel yang akan diambil adalah seorang Ibu yang mempunyai anak usia 1-3 tahun mengalami Gerakan Tutup Mulut (GTM), berumur $>18$ tahun, tidak mengalami gangguan mental dan fisik, serta bersedia menjadi responden.

Penelitian di lakukan di Rumas Sakit Umum Universitas Muhammadiyah Malang pada bulan Desember 2020-Januari 2021. Responden mengisi kuisioner yang berupa google form yang terdiri dari beberapa pertanyaan. Sebelum mengisi kuisioner responden akan dijelaskan terlebih dahulu tentang petunjuk pengisian kuisioner. Formulir kuisioner terdiri dari tiga bagian. Bagian pertama adalah untuk formulir persetujuan sebagai responden, Bagian kedua untuk data umum yang merupakan karakteristik responden. Data karakteristik responden meliputi data tentang umur, pendidikan, pekerjaan, jenis kelamin anak, dan pengasuhan anak. Bagian ketiga dipergunakan untuk mengukur tingkat pengetahuan ibu tentang feeding rules.

Bagian tiga Terdiri dari 14 pertanyaan, jawaban yang benar diberikan skor 1 , jawaban salah diberikan skor 0 . Pertanyaan nomor 1,2,3,4,5,7,14 jawaban yang benar adalah Ya sedangkan pertanyaan nomor $6,8,9,10,11,12,13$ jawaban yang benar adalah Tidak. Pertanyaan dibuat dalam bentuk skala Guttman yaitu skala yang bersifat tegas dan konsisten dengan memberikan, jawaban tegas pada pertanyaan. 
Tabel 1. Distribusi Persebaran Responden

\begin{tabular}{lcc}
\hline Variabel & $\begin{array}{c}\text { Jumlah } \\
\text { (N=67) }\end{array}$ & $\begin{array}{c}\text { Presentase } \\
(\%)\end{array}$ \\
\hline Usia & 46 & 69 \\
$26-35$ tahun & 21 & 31 \\
$36-45$ tahun & & \\
Pendidikan & 0 & 0 \\
SD & 1 & 1 \\
SMP & 8 & 12 \\
SMA & 58 & 87 \\
SARJANA/ & & \\
DIPLOMA & & \\
Pekerjaan & 29 & 43 \\
Ibu Rumah Tangga (IRT) & 7 & 10 \\
Dokter & 6 & 9 \\
Perawat & 12 & 18 \\
Karyawan & 6 & 9 \\
Dosen & 5 & 8 \\
Wirausaha & 2 & 3 \\
Lainnya & & \\
Pengasuhan Anak & & 84 \\
Diasuh sendiri & 56 & 16 \\
Diasuh orang lain & 11 & 42 \\
Jenis Kelamin Anak & & 58 \\
Laki-laki & 28 & \\
Perempuan & 39 & \\
\hline & & \\
\hline
\end{tabular}

Responden harus memilih salah satu dari jawaban yang telah disediakan yaitu Ya atau Tidak dengan memberikan tanda check list $(\sqrt{ })$. Sebelumnya kuisioner telah dilakukan uji validasi kepada 20 orang responden, dimana responden tidak diikutsertakan dalam penelitian sebenarnya. Uji validitas dan reliabilitas telah dilakukan dengan nilai Cronbach Alpha 0,899. Analisa data yang dilakukan peneliti adalah analisa univariat.

\section{Hasil dan Pembahasan}

Hasil penelitian yang didapatkan berupa data demografi dan data tingkat pengetahuan. Perhitungan data demografi dilakukan untuk melihat frekuensi/proporsi dan persentase berdasarkan karakteristik responden yaitu: kelompok umur ibu, pendidikan ibu, pekerjaan ibu, jenis kelamin anak, dan pengasuhan anak. Berdasarkan tabel 1, distribusi persebaran responden menurut usia responden sebagian besar responden berusia 26 - 35 tahun yaitu sebanyak 46 responden (69\%), sedangkan yang berusia 36 - 45 tahun sebanyak 21 responden
(31\%). Distribusi persebaran responden menurut tingkat pendidikan responden sebagian besar responden adalah Sarjana/Diploma yaitu sebanyak 59 responden (87\%), sedangkan tingkat pendidikan SMA sebanyak 8 responden (12\%), dan SMP sebanyak 1 responden $(1 \%)$.

Distribusi persebaran responden menurut pekerjaan sebagian besar responden adalah ibu rumah tangga yaitu sebanyak 29 responden (43\%), dokter sebanyak 7 responden (10\%), perawat sebanyak 6 responden $(9 \%)$, karyawan sebanyak 12 responden (18\%), dosen sebanyak 6 responden (9\%), wirausaha sebanyak 5 responden $(8 \%)$, lainnya sebanyak 2 responden (3\%). Distribusi persebaran responden menurut pengasuhan anak sebagian besar responden mengasuh anak sendiri yaitu sebanyak 56 responden (84\%), sedangkan yang diasuh oleh orang lain sebanyak 11 responden (16\%). Distribusi persebaran responden menurut jenis kelamin anak sebagian besar jenis kelamin anak laki-laki yaitu sebanyak 28 responden (42\%), sedangkan jenis kelamin anak perempuan sebanyak 39 responden (58\%).

Tabel 2. Persebaran Tingkat Pengetahuan Ibu

\begin{tabular}{lcc}
\hline $\begin{array}{l}\text { Tingkat } \\
\text { Pengetahuan }\end{array}$ & $\begin{array}{c}\text { Jumlah } \\
(\mathbf{N}=67)\end{array}$ & $\begin{array}{c}\text { Presentase } \\
(\%)\end{array}$ \\
\hline Baik & 38 & 57 \\
Kurang & 29 & 4 \\
\hline
\end{tabular}

Berdasarkan tabel 2 hasil penelitian didapatkan tingkat pengetahuan ibu tentang Feeding rules pada anak usia 1-3 tahun yang mengalami Gerakan Tutup Mulut (GTM) adalah baik yaitu, sebanyak 38 responden (57\%), sedangkan yang memiliki tingkat pengetahuan kurang sebanyak 29 responden (43\%). Hasil ini menunjukkan meski tingkat pengetahuan ibu tentang feeding rules baik, anak masih mengalami masalah Gerakan Tutup Mulut (GTM). Hal ini sejalan dengan penelitian dari Maulidya pada tahun 2020, yakni ibu dengan perilaku makan yang baik sebesar $71 \%$ tidak menjamin anaknya tidak mengalami masalah GTM. ${ }^{9}$ 
Terjadinya GTM dapat dikarenakan adanya faktor internal didalam tubuh baduta itu sendiri seperti infeksi, tubuh yang sedang sakit, tumbuh gigi atau hal yang lainnya. Karena masalah GTM yang terjadi tidak berlangsung pada waktu yang lama dan akan pulih ketika keadaan tubuh kembali pulih seperti sebelumnya. GTM juga dapat disebabkan oleh jenis dan bentuk makanan yang kurang diperhatikan. ${ }^{9}$

Tabel 3. Persebaran Tingkat Pengetahuan Ibu Berdasarkan Pengasuhan Anak

\begin{tabular}{|c|c|c|c|c|c|c|}
\hline \multirow{3}{*}{ Pengasuhan } & \multicolumn{4}{|c|}{$\begin{array}{c}\text { Tingkat } \\
\text { Pengetahuan }\end{array}$} & \multirow{2}{*}{\multicolumn{2}{|c|}{ Total }} \\
\hline & \multicolumn{2}{|c|}{ Baik } & \multicolumn{2}{|c|}{ Kurang } & & \\
\hline & $\mathrm{N}$ & $(\%)$ & $\mathrm{N}$ & $(\%)$ & $\mathrm{N}$ & $(\%)$ \\
\hline $\begin{array}{l}\text { Diasuh Orang } \\
\text { Lain }\end{array}$ & 6 & 54 & 5 & 46 & 11 & 100 \\
\hline Diasuh Sendiri & 32 & 57 & 24 & 43 & 56 & 100 \\
\hline
\end{tabular}

Dari hasil penelitian pada tabel 3 didapatkan bahwa pada anak yang diasuh sendiri serta mengalami Gerakan Tutup Mulut (GTM) sebanyak 32 responden (57\%) yakni ibu memiliki tingkat pengetahuan baik dan 24 (43\%) responden memiliki tingkat pengetahuan kurang. Sedangkan pada anak yang diasuh oleh orang lain serta mengalami GTM sebanyak 6 (54\%) responden memiliki tingkat pengetahuan yang baik tentang Feeding rules dan 5 (46\%) responden memiliki tingkat pengetahuan kurang.

Hal ini dapat disebabkan karena pola pengasuhan yang kurang tepat oleh orang tua utamanya terhadap kebiasaan makan. Hal ini sejalan dengan penelitian Karaki pada tahun 2016, tentang pola asuh ibu dengan perilaku sulit makan pada anak usia prasekolah. Penelitian tersebut menunjukan bahwa pola asuh sangat mempengaruhi tumbuh kembang anak terlebih kebiasaan makan sehingga pola asuh yang kurang baik dapat menyebabkan anak mengalami perilaku sulit makan. ${ }^{6}$

Pola asuh makan yang kurang baik meliputi tidak adanya penerapan jadwal dan aturan makan (Feeding rules). Penelitian yang dilakukan oleh Mundijah pada tahun 2020 menunjukkan bahwa terdapat pengaruh yang signifikan antara penerapan Feeding rules terhadap kesulitan makan kelompok picky eater dan small eater. Feeding rules menurut WHO meliputi: jadwal, lingkungan, dan prosedur makan. ${ }^{10,14}$

Jadwal makan menurut WHO sehari meliputi adanya jadwal makan utama, dan makan selingan yang teratur, serta durasi makan maksimal 30 menit. Anak tidak diberi air minum kecuali hanya disela makan utama. Tidak sedikit orang tua atau pengasuh memberikan makan pada anak tanpa jadwal, misalnya memberikan anak minuman (susu atau air putih) atau snack menjelang jam makan utama yang mengakibatkan anak kenyang sebelum ia makan. ${ }^{10,14}$

Lingkungan saat makan yang mendukung akan tercipta kebiasaan makan yang baik tanpa adanya paksaan, tidak ada distraksi saat makan,misalnya TV, game, atau mainan, serta tidak ada hadiah bila telah makan. ${ }^{10} \mathrm{Hal}$ ini juga didukung dari penelitian oleh Maulidya pada tahun 2020 yakni terdapat beberapa perilaku yang kurang tepat yang dilakukan responden dalam proses makan pada baduta yaitu memberikan distraksi berupa tontonan youtube melalui telepon genggam atau tayangan televise agar makanan mudah masuk ke dalam mulut dan anak mau makan. Baduta pada saat diberikan makanan lebih banyak diberikan tontonan agar anak mudah untuk membuka mulut. ${ }^{8}$

Proses makan adalah proses belajar mengenal rasa, bau, tekstur dan suhu. Prosedur: mendorong anak untuk makan sendiri, menawari anak tanpa ada paksaan atau reward, bila setelah 10-15 menit anak tetap tidak mau makan, akhiri proses makan. Praktik pemberian makan melibatkan pendengaran, penglihatan, rasa, dan indera perasa anak, jika saat proses pemberian makan anak mengalami pengalaman buruk berupa pemaksaan maka akan menimbulkan trauma tersendiri, sehingga berdampak negatif untuk periode usia berikutnya. ${ }^{10}$ 
Tabel 4. Persebaran Tingkat Pengetahuan Ibu Berdasarkan Jenis Kelamin Anak

\begin{tabular}{lcccccc}
\hline \multirow{2}{*}{$\begin{array}{l}\text { Jenis } \\
\text { Kelamin }\end{array}$} & \multicolumn{3}{c}{ Tingkat Pengetahuan } & \multicolumn{2}{c}{ Total } \\
\cline { 2 - 6 } & \multicolumn{2}{c}{ Baik } & \multicolumn{2}{c}{ Kurang } & \multicolumn{2}{c}{} \\
\cline { 2 - 6 } & $\mathrm{N}$ & $(\%)$ & $\mathrm{N}$ & $(\%)$ & $\mathrm{N}$ & $(\%)$ \\
\hline Laki-laki & 13 & 46 & 15 & 54 & 28 & 100 \\
Perempuan & 25 & 64 & 14 & 36 & 39 & 100 \\
\hline
\end{tabular}

Dari hasil penelitian pada tabel 4 didapatkan tingkat pengetahuan ibu terhadap Feeding rules pada anak yang mengalami GTM berjenis kelamin laki-laki sebanyak 13 (46\%) responden memiliki tingkat pengetahuan baik dan 15 (54\%) responden memiliki tingkat pengetahuan kurang. Sedangkan pada jenis kelamin perempuan sebanyak 25 (64\%) responden memiliki tingkat pengetahuan baik dan $14(36 \%)$ responden memiliki tingkat pengetahuan kurang. Diketahui dari hasil ini bahwa pada jenis kelamin anak perempuan yang lebih banyak mengalami GTM daripada anak laki-laki, sang Ibu sudah memiliki pengetahuan tentang feeding rules yang baik.

Hasil ini tidak sejalan dengan penelitian dari Kesuma pada tahun 2016 tentang Faktor Faktor yang Berhubungan dengan Perilaku Kesulitan Makan Anak Prasekolah yang mengatakan bahwa anak laki-laki lebih tantrum daripada anak perempuan sehingga lebih banyak mengalami kesulitan makan ${ }^{6}$. Pengetahuan ibu yang baik tentang feeding rules apabila tidak didukung dengan pola asuh yang. Pola asuh ibu sangat penting dalam tumbuh kembang anak dalam psikologis anak, kemampuan bersosialisasi anak, kemandirian anak, serta perilaku sulit makan pada anak. Sikap ibu dapat membentuk karakter anak menjadi sulit makan adalah cara menyiapkan makanan, cara memberikan anak makan, menenangkan anak dengan memberikan makanan ringan, memaksa anak untuk makan, terlambat memberikan makanan padat, dan ibu tidak membiasakan anak makan tepat waktu. ${ }^{7,14}$

\section{Kesimpulan}

Tingkat pengetahuan ibu tentang (feeding rules) terhadap masalah GTM pada anak usia 1-3 tahun memiliki pengetahuan yang baik. Pada anak yang diasuh oleh orang tuanya sendiri tingkat pengetahuan ibu tentang (Feeding rules) terhadap masalah GTM pada anak usia 1-3 memiliki pengetahuan baik. Pada anak berjenis kelamin laki-laki tingkat pengetahuan ibu tentang (feeding rules) terhadap masalah GTM pada anak usia 1-3 tahun memiliki tingkat pengetahuan baik. Tingkat pengetahuan yang baik belum tidak menjamin anak tidak mengalami GTM.

Dengan adanya penelitian diharapkan tenaga kesehatan lebih giat untuk mempromosikan tentang pentingnya Feeding rules pada ibu yang mempunyai anak utamanya batita. Masalah makan akan mudah timbul pada batita utamanya bila anak tidak diasuh oleh orang tua sendiri. Tingkat pengetahuan yang baik tentang Feeding rules bila tidak didukung dengan perilaku makan dari orang tua yang baik akan tetap menimbulkan masalah GTM pada anak.

\section{Ucapan Terima Kasih}

Penulis mengucapkan terima kasih kepada para pihak yang telah memberi dukungan dan kontribusi terhadap penelitian ini khususnya Rumah Sakit Umum Universitas Muhammdiyah Malang.

\section{Referensi}

1. Aprillia YT, Mawarni ES, Agustina S. Pengetahuan Ibu Tentang Makanan Pendamping ASI (MP-ASI). J Ilm Kesehat Sandi Husada. 2020;12(2):865-872.

2. Widjaja NA. Identifikasi dan Tatalaksana Masalah Makan Pada Bayi dan Anak. Cetakan I. Rahmatyah R, editor. Surabaya: Saga Jawadwipa; 2018.

3. Darwati D, Mexitalia M, Hadiyanto $S$, Hartanto F, Nugraheni SA. Pengaruh Intervensi Konseling Feeding rules dan Stimulasi Terhadap Status Gizi dan Perkembangan Anak di Posyandu Kabupaten Jayapura. Sari Pediatr. 2016;15(6):377-384.

4. Unit Kerja Koordinasi Nutrisi dan Penyakit Metabolik Ikatan Dokter Anak Indonesia. Pemberian Makanan Pendamping Air Susu 
Ibu (MPASI). Jakarta: UKK Nutrisi dan Penyakit Metabolik IDAI; 2018.

5. Karaki KB, Kundre R, Karunden $M$. Hubungan Pola Asuh Ibu Dengan Perilaku Sulit Makan Pada Anak Usia Prasekolah (35 Tahun) Di Taman Kanak-Kanak Desa Palelon Kec. Modoinding Minahasa Selatan. ejournal Keperawatan (e-Kp). 2016;4(1):17.

6. Kesuma A, Novayelinda R, Sabrian F. Faktor-faktor yang Berhubungan dengan Perilaku Kesulitan Makan Anak Pra Sekolah. Ramanujan J. 2015;2(2):953-61.

7. Nafratilawati M, Saparwati M, Rosalina. Hubungan Antara Pola Asuh Dengan Kesulitan MakanPada Anak Prasekolah (3-5 Tahun) Di Tk Leyangan Kabupaten Semarang. J Gizi dan Kesehat. 2015;7(14):64-71.

8. Maulidiya H, Muniroh L. Hubungan Perilaku Ibu Dalam Pemberian MP - ASI Dengan Kejadian Gerakan Tutup Mulut (GTM) Dan Status Gizi Pada Baduta. Media Gizi dan Kesmas. 2020;9(1):23-29.

9. Munjidah A, Rahayu EP. Pengaruh Penerapan Feeding rules Sebagai Upaya Mengatasi Kesulitan Makan Pada Anak (Picky Eater, Selective Eater Dan Small Eater). JKM (Jurnal Kesehat Masyarakat) Cendekia Utama. 2020;8(1):29-39.

10. Abu Naser SS, Alawar MW. Knowledge Based Intelligent System for Feeding Problems in Infants and Children. Int J Med Res. 2016;1(2):79-82.

11. Notoatmodjo. Pendidikan dan Perilaku Kesehatan. Edisi Revisi. Rineka Cipta. Jakarta; 2012.
12. Unit Kerja Koordinasi Nutrisi dan Penyakit Metabolik Ikatan Dokter Anak Indonesia. Rekomendasi Ikatan Dokter Anak Indonesia. Pendekatan Diagnosis dan Tata Laksana Masalah Makan pada Batita di Indonesia.

Jakarta: Unit Kerja Koordinasi Nutrisi dan Penyakit Metabolik Ikatan Dokter Anak Indonesia; 2014.

13. Unit Kerja Koordinasi Nutrisi dan Penyakit Metabolik Ikatan Dokter Anak Indonesia. Rekomendasi Praktik Pemberian Makan Berbasis Bukti pada Bayi dan Batita di Indonesia untuk Mencegah Malnutrisi. Jakarta: Unit Kerja Koordinasi Nutrisi dan Penyakit Metabolik Ikatan Dokter Anak Indonesia; 2015.

14. Riswan, Yunitasari E. Hubungan antara pengasuhan orangtua dengan masalah makan pada anak usia prasekolah. Maj Kesehat Indones. 2020;1(1):21-4. 